\title{
Serum Concentrations of Fibroblast Growth Factor 19 in Patients With Obesity and Type 2 Diabetes Mellitus: the Influence of Acute Hyperinsulinemia, Very-Low Calorie Diet and PPAR-a Agonist Treatment
}

\author{
M. MRÁZ ${ }^{1}$, Z. LACINOVÁ ${ }^{1}$, P. KAVÁLKOVÁ ${ }^{1}$, D. HALUZÍKOVÁ ${ }^{1,2}$, P. TRACHTA ${ }^{1}$, \\ J. DRÁPALOVÁ ${ }^{1}$, V. HANUŠOVÁ ${ }^{1}$, M. HALUZÍK ${ }^{1}$ \\ ${ }^{1}$ Third Department of Medicine, General University Hospital and First Medical Faculty, Charles \\ University, Prague, Czech Republic, ${ }^{2}$ Department of Sports Medicine, General University Hospital \\ and First Medical Faculty, Charles University, Prague, Czech Republic
}

Received October 12, 2010

Accepted April 7, 2011

On-line May 16, 2011

\section{Summary}

The aim of our study was to measure serum concentrations of fibroblast growth factor 19 (FGF-19) in patients with obesity (OB), obesity and type 2 diabetes mellitus (T2DM) and healthy subjects (C) at baseline and after selected interventions. We measured serum FGF-19 levels and other biochemical and hormonal parameters in $29 \mathrm{OB}$ and 19 T2DM females and 30 sexand age-matched control subjects. The interventions were acute hyperinsulinemia during isoglycemic-hyperinsulinemic clamp ( $n=11$ for T2DM and 10 for $C$ ), very-low calorie diet (VLCD, $n=12$ for $\mathrm{OB}$ ) and 3 months treatment with PPAR- $\alpha$ agonist fenofibrate ( $n=11$ for T2DM). Baseline serum FGF-19 levels were significantly lower in $\mathrm{OB}$ relative to $\mathrm{C}$ group (132.1 \pm 12.7 vs. $202.2 \pm 16.7$ $\mathrm{pg} / \mathrm{ml}, \mathrm{p}<0.05)$, while no significant difference was observed between T2DM and $\mathrm{OB}$ or control group. Acute hyperinsulinemia tended to decrease FGF-19 levels in both healthy and T2DM subjects. Three weeks of VLCD in OB group had no significant effect on FGF-19, whereas three months of fenofibrate treatment markedly reduced FGF-19 levels in T2DM patients (194.58 \pm 26.2 vs. $107.47 \pm 25.0 \mathrm{pg} / \mathrm{ml}, \mathrm{p}<0.05)$. We conclude that FGF-19 levels in our study were at least partially dependent upon nutritional status, but were not related to parameters of glucose metabolism or insulin sensitivity.

\section{Key words}

FGF-19 • Obesity • Type 2 diabetes mellitus • Very low calorie diet $\bullet$ Fenofibrate

\section{Corresponding author}

M. Haluzík, U nemocnice 1, 12808 Prague 2, Czech Republic. E-mail: mhalu@If1.cuni.cz

\section{Introduction}

Fibroblast growth factor 19 (FGF-19) is a recently identified endocrine regulator with multiple effects on metabolic processes and energy homeostasis (Nishimura et al. 1999, Xie et al. 1999, Itoh and Ornitz 2004). Produced predominantly in enterocytes of terminal ileum under the regulation of Farnesoid $\mathrm{X}$ receptor (FXR), a bile acid nuclear receptor, and acting mainly in liver through fibroblast growth factor receptor 4 (FGFR4), FGF-19 has been demonstrated to play a central role in the negative feedback loop of bile acid synthesis and gallbladder refilling (Yu et al. 2000, Holt et al. 2003, Inagaki et al. 2005, Yu et al. 2005, Choi et al. 2006). Animal studies have also shown antiadipogenic, anti-diabetic and hypolipidemic effects of either exogenous administration or endogenous overexpression of FGF-19 with altered expression of a number of genes involved especially in lipid metabolism (Tomlinson et al. 2002, Fu et al. 2004).

In contrast to animals, only limited data on FGF-19 concentrations, regulation and function are available in humans. In the first study conducted in healthy human volunteers, serum FGF-19 levels exerted a 
pronounced diurnal rhythm following the rise in serum bile acids, which was abolished upon fasting. Treatment with bile acid sequestrants decreased FGF-19 concentrations, while administration of chenodeoxycholic acid had opposite effect (Lundasen et al. 2006). In two other studies circulating FGF-19 was found to be increased in patients with end-stage renal disease and extrahepatic cholestasis caused by tumorous obstruction of biliary ducts (Schaap et al. 2009, Reiche et al. 2010). Chronically malnourished patients with anorexia nervosa did not show any changes in systemic FGF-19 compared to normal-weight subjects (Dostalova et al. 2008b). The only two trials exploring in part the relation of FGF-19 to glucose metabolism disorders could not find significant difference in its circulating levels between patients with type 2 diabetes mellitus or insulin resistance relative to healthy controls (Brufau et al. 2010, Schreuder et al. 2010).

To our best knowledge, no targeted information about the influence of obesity on circulating FGF-19 levels is available, nor are any data about the dynamic changes in FGF-19 concentrations after dietary intervention or acute hyperinsulinemia. The main regulator of FGF-19 production FXR is an important link between bile acid and triglyceride metabolism, interacting with a variety of genes and receptors, among others PPAR- $\alpha$ (Smelt 2010). The exact role of FGF-19 in these interactions and the influence of lipid-lowering PPAR- $\alpha$ agonists on FGF-19 levels are largely unknown as well. In the present study we therefore addressed the question whether circulating FGF-19 levels are influenced by increased body weight and the presence of T2DM and whether any changes in its concentrations could contribute to positive metabolic effects of very-low calorie diet in patients with obesity or lipid-lowering therapy with PPAR- $\alpha$ agonists in subjects with obesity and type 2 diabetes. To this end we measured serum FGF-19 concentrations in patients with obesity and T2DM and studied its changes after above mentioned interventions.

\section{Methods}

\section{Study subjects and interventions}

Overall, 29 women with obesity (defined as BMI $\geq 30$ ) without type 2 diabetes mellitus, 19 women with obesity and type 2 diabetes mellitus and 30 age-matched healthy control women were included into the study. The body weight of all study participants remained stable for at least 3 months before the beginning of the study.
Very low calorie diet sub-study

12 out of 29 obese subjects without type 2 diabetes mellitus underwent a 3-week very low calorie diet (VLCD) program. They were hospitalized in the Third Department of Medicine, General University Hospital, Prague and were given a very low calorie diet with energy content of $2500 \mathrm{~kJ} /$ day.

\section{Fenofibrate treatment sub-study}

11 obese females with type 2 diabetes mellitus and 10 non-obese women were included into fenofibrate intervention study, which was described in detail elsewhere (Haluzik et al. 2009). T2DM patients were treated with diet, metformin alone or combination of metformin and glimepiride before the beginning of the study. Diabetic medication remained unchanged from three months before the start throughout the entire study. Diabetic subjects were treated with PPAR- $\alpha$ agonist fenofibrate (Lipanthyl M 267) for three months. Their insulin sensitivity before and after 3 months of fenofibrate treatment was examined by isoglycemichyperinsulinemic clamp as described previously (Anderlova et al. 2007). Ten lean healthy non-diabetic subjects, who were free of any medication, underwent a single isoglycemic-hyperinsulinemic clamp and served as a control group in fenofibrate intervention study.

Written informed consent was signed by all participants before being enrolled into the study. The study was approved by the Human Ethical Review Committee, First Faculty of Medicine and General University Hospital, Prague, Czech Republic and was performed in accordance with the principles of the Declaration of Helsinki as revised in 2000.

\section{Anthropometric examination, blood and tissue sampling}

All subjects were measured and weighted and their body mass index (BMI) was calculated. Blood samples were withdrawn between 07:00 $\mathrm{h}$ and 08:00 h after overnight fasting. Blood samples were separated by centrifugation for 10 minutes at 1000x g within 30 minutes from blood collection. Serum was subsequently stored in aliquots at $-70^{\circ} \mathrm{C}$ until further analysis.

Clinical and hormonal parameters in obese patients on VLCD were measured one day before the beginning of the diet and at the end of the third week of VLCD. Clinical and hormonal parameters in type 2 diabetes patients in the fenofibrate substudy were measured at baseline and after 3 months of treatment with PPAR- $\alpha$ agonist fenofibrate (200 mg, Lipanthyl 267M). 
Table 1. Anthropometric, biochemical and hormonal characteristics of control group of healthy women (Control), obese women without type 2 diabetes mellitus (Obese) and type 2 diabetic women (T2DM). Values are means \pm S.E.M. Statistical significance is from Oneway ANOVA or ANOVA on Ranks as appropriate. ${ }^{*} p<0.05$ vs. control group; ${ }^{\circ} p<0.05$ T2DM vs. Obese.

\begin{tabular}{lccc}
\hline Group & Control & Obese & T2DM \\
\hline Number of subjects & 30 & 29 & 19 \\
Age $($ years) & $48.4 \pm 2.2$ & $45.9 \pm 1.4$ & $51.4 \pm 1.5$ \\
BMI $\left(\mathrm{kg} / \mathrm{m}^{2}\right)$ & $23.8 \pm 0.3$ & $44.6 \pm 1.5^{*}$ & $36.7 \pm 1.2^{* \circ}$ \\
Blood glucose (mmol/l) & $4.30 \pm 0.23$ & $5.72 \pm 0.33^{*}$ & $10.07 \pm 0.84^{* \circ}$ \\
Cholesterol $(\mathrm{mmol} / \mathrm{l})$ & $5.07 \pm 0.17$ & $4.99 \pm 0.23$ & $4.38 \pm 0.21$ \\
Triglycerides $(\mathrm{mmol} / \mathrm{l})$ & $1.16 \pm 0.11$ & $1.68 \pm 0.15^{*}$ & $2.82 \pm 0.26^{* \circ}$ \\
Insulin $(\mathrm{mIU} / \mathrm{l})$ & $14.72 \pm 1.65$ & $24.59 \pm 2.34^{*}$ & $46.60 \pm 4.02^{* \circ}$ \\
HOMA index & $2.50 \pm 0.48$ & $6.06 \pm 0.66^{*}$ & $18.05 \pm 1.46^{* \circ}$ \\
Leptin $(\mathrm{ng} / \mathrm{ml})$ & $12.57 \pm 1.54$ & $47.67 \pm 2.19^{*}$ & $28.1 \pm 3.30^{* \circ}$ \\
Adiponectin $(\mu \mathrm{g} / \mathrm{ml})$ & $22.23 \pm 1.88$ & $14.94 \pm 1.19^{*}$ & $13.02 \pm 2.11^{*}$ \\
\hline
\end{tabular}

\section{Hormonal and biochemical assays}

Serum FGF-19 levels were measured by a sandwich enzyme immunoassay (BioVendor, Brno, Czech Republic), following the manufacturer's instructions. Serum samples for FGF-19 measurement were diluted 1:1 with a dilution buffer prior to the assay. The standard curve range for the assay was $15.0-960.0 \mathrm{ng} / \mathrm{ml}$. Sensitivity was $4.8 \mathrm{pg} / \mathrm{ml}$ and the intra- and interassay variability was 3-8 $\%$ and $10-13 \%$, respectively. Serum insulin concentrations were measured by commercial RIA kit (Cis Bio International, Gif-sur-Yvette Cedex, France). Sensitivity was $2.0 \mu \mathrm{IU} / \mathrm{ml}$. Serum adiponectin levels were measured by commercial ELISA kit (Linco Research, St. Charles, Missouri, USA). Sensitivity was $0.78 \mathrm{ng} / \mathrm{ml}$. Serum leptin concentrations were measured by commercial ELISA kit (Biovendor, Brno, Czech Republic). Sensitivity was $0.17 \mathrm{ng} / \mathrm{ml}$. The intra- and interassay variability of all kits was less than $5.0 \%$ and $9.0 \%$ respectively.

Biochemical parameters were measured in the Department of Biochemistry of General University Hospital, Prague by standard laboratory methods. Homeostasis model assessment (HOMA-R) index was calculated as previously described (Matthews et al. 1985) using the following formula:

fasting serum insulin $(\mathrm{mIU} / \mathrm{l}) \times$ fasting serum glucose $(\mathrm{mmol} / \mathrm{l}) / 22.5$.

\section{Statistical analysis}

Statistical analysis was performed using SigmaStat software (SPSS Inc., Chicago, IL). The results are expressed as means \pm standard error means (S.E.M.). Changes in FGF-19 and hormonal parameters between studied groups were evaluated by One-way ANOVA followed by Holm-Sidak method or ANOVA on Ranks followed by Dunn's test and Paired t-test or Wilcoxon Signed Rank Test as appropriate. Changes of FGF-19 during the clamp were analyzed by One-way RM ANOVA on Ranks followed by Dunn's method. Spearman or Pearson correlation test and multiple regression analysis were used to calculate the relationships between FGF-19 levels and other parameters. Statistical significance was assigned to $\mathrm{p}<0.05$.

\section{Results}

Baseline characteristics of patients with obesity, patients with type 2 diabetes mellitus and control group

Anthropometric, biochemical and hormonal characteristics of obese, T2DM, and control group are shown in Table 1. As expected, BMI, blood glucose levels, HOMA index, serum triglyceride, leptin and insulin concentrations were significantly higher in both obese and T2DM group relative to control subjects. On the contrary, adiponectin levels were significantly lower in both of these groups. No differences in serum cholesterol were found between the groups. When comparing T2DM with obese group, diabetic patients had significantly lower BMI and leptin levels, while blood glucose, triglycerides, insulin and HOMA index were significantly higher in T2DM group relative to obese subjects.

Anthropometric and clinical characteristics of patients included into VLCD study

The influence of VLCD on anthropometric, 
Table 2. Anthropometric, biochemical and hormonal characteristics of control group of healthy women (Control) and obese female subjects before (Obese Baseline) and after (Obese after VLCD) three weeks of VLCD. Values are means \pm S.E.M. Statistical significance is from One-way ANOVA or ANOVA on Ranks (Obese Baseline or Obese after VLCD vs. Controls) and from Paired t-test or Wilcoxon Signed Rank Test (Obese Baseline vs. Obese after VLCD) as appropriate. ${ }^{*} p<0.05$ vs. control group; ${ }^{\circ} p<0.05$ Obese Baseline vs. Obese after VLCD.

\begin{tabular}{lccc} 
Group & Control & Baseline & Obese \\
& & 12 & 12 \\
Number of subjects & 30 & $49.5 \pm 2.7^{*}$ & $47.1 \pm 2.5^{* \circ}$ \\
BMI $\left(\mathrm{kg} / \mathrm{m}^{2}\right)$ & $23.8 \pm 0.3$ & $5.91 \pm 0.47^{*}$ & $5.26 \pm 0.26^{*}$ \\
Blood $\mathrm{glucose}(\mathrm{mmol} / \mathrm{l})$ & $4.30 \pm 0.23$ & $4.50 \pm 0.23$ & $4.12 \pm 0.22$ \\
Cholesterol $(\mathrm{mmol} / \mathrm{l})$ & $5.07 \pm 0.17$ & $1.37 \pm 0.01$ & $1.17 \pm 0.10$ \\
Triglycerides $(\mathrm{mmol} / \mathrm{l})$ & $1.16 \pm 0.11$ & $34.03 \pm 3.56^{*}$ & $30.34 \pm 4.11^{*}$ \\
Insulin $(\mathrm{mIU} / \mathrm{l})$ & $14.72 \pm 1.65$ & $8.53 \pm 1.09^{*}$ & $6.57 \pm 0.88^{* \circ}$ \\
HOMA index & $2.50 \pm 0.48$ & $45.83 \pm 3.89^{*}$ & $42.47 \pm 4.77^{*}$ \\
Leptin $(\mathrm{ng} / \mathrm{ml})$ & $12.57 \pm 1.54$ & $13.66 \pm 1.45^{*}$ & $14.33 \pm 1.52^{*}$ \\
Adiponectin $(\mu \mathrm{g} / \mathrm{ml})$ & $22.23 \pm 1.88$ & & \\
\hline
\end{tabular}

Table 3. Anthropometric, biochemical and hormonal characteristics of control group of healthy females (Control) and obese type 2 diabetic women before (T2DM baseline) and after three months of treatment with PPAR-a agonist fenofibrate (T2DM fenofibrate). Values are means \pm S.E.M. Statistical significance is from One-way ANOVA or ANOVA on Ranks as appropriate (T2DM/Baseline or T2DM/Fenofibrate vs. Controls) and from Paired t-test or Wilcoxon Signed Rank Test (T2DM/Baseline vs. T2DM/Fenofibrate) $* \mathrm{p}<0.05$ vs. control group; ${ }^{\circ} \mathrm{p}<0.05 \mathrm{~T} 2 \mathrm{DM} /$ Fenofibrate vs. T2DM/baseline.

\begin{tabular}{|c|c|c|c|}
\hline \multirow{2}{*}{ Group } & \multirow{2}{*}{ Control } & \multicolumn{2}{|c|}{ T2DM } \\
\hline & & Baseline & Fenofibrate \\
\hline Number of subjects & 10 & 11 & 11 \\
\hline$B M I\left(\mathrm{~kg} / \mathrm{m}^{2}\right)$ & $23.7 \pm 0.8$ & $36.7 \pm 2.9^{*}$ & $36.5 \pm 2.7 *$ \\
\hline Blood glucose (mmol/l) & $4.97 \pm 0.19$ & $8.48 \pm 0.68^{*}$ & $9.43 \pm 0.84 * \circ$ \\
\hline Glycated Hemoglobin (\%) & $3.81 \pm 0.08$ & $5.77 \pm 0.56^{*}$ & $6.10 \pm 0.58^{* \circ}$ \\
\hline Cholesterol (mmol/l) & $5.39 \pm 0.24$ & $5.22 \pm 0.32$ & $5.09 \pm 0.25$ \\
\hline HDL-cholesterol (mmol/l) & $1.55 \pm 0.28$ & $1.17 \pm 0.11^{*}$ & $1.20 \pm 0.11^{*}$ \\
\hline Triglycerides (mmol/l) & $0.98 \pm 0.12$ & $2.96 \pm 0.39^{*}$ & $2.17 \pm 0.24 * \circ$ \\
\hline Insulin (mIU/l) & $23.0 \pm 2.9$ & $44.2 \pm 7.1^{*}$ & $47.5 \pm 8.0^{*}$ \\
\hline HOMA index & $5.08 \pm 0.56$ & $16.66 \pm 0.21^{*}$ & $20.12 \pm 0.30^{* \circ}$ \\
\hline Adiponectin $(\mu \mathrm{g} / \mathrm{ml})$ & $22.41 \pm 1.82$ & $17.46 \pm 4.04$ & $16.53 \pm 2.56$ \\
\hline Atherogenic index & $1.88 \pm 0.09$ & $3.17 \pm 0.37^{*}$ & $3.02 \pm 0.75^{*}$ \\
\hline
\end{tabular}

biochemical and hormonal parameters is summarized in Table 2. At baseline, patients with obesity had significantly higher BMI, blood glucose, serum insulin, HOMA index and leptin and lower serum adiponectin relative to control subjects. The groups did not significantly differ in serum triglyceride and cholesterol levels. VLCD induced a significant decrease in BMI and HOMA index. Insulin, glucose and leptin concentrations tended to decrease after VLCD, but the difference did not reach the statistical significance. No significant influence of VLCD on serum cholesterol, triglyceride and adiponectin levels was found.
Anthropometric and clinical characteristics of patients included into fenofibrate treatment study

Anthropometric, biochemical and hormonal characteristics of the study sub-group have been described in detail elsewhere (Haluzik et al. 2009) and are briefly shown in Table 3. At baseline, BMI, blood glucose, serum triglyceride, insulin, glycated hemoglobin and atherogenic index were significantly higher, while serum HDL cholesterol was significantly lower in T2DM group relative to control subjects. Three months of treatment with fenofibrate led to a significant decrease of 


\section{Serum FGF 19 levels}

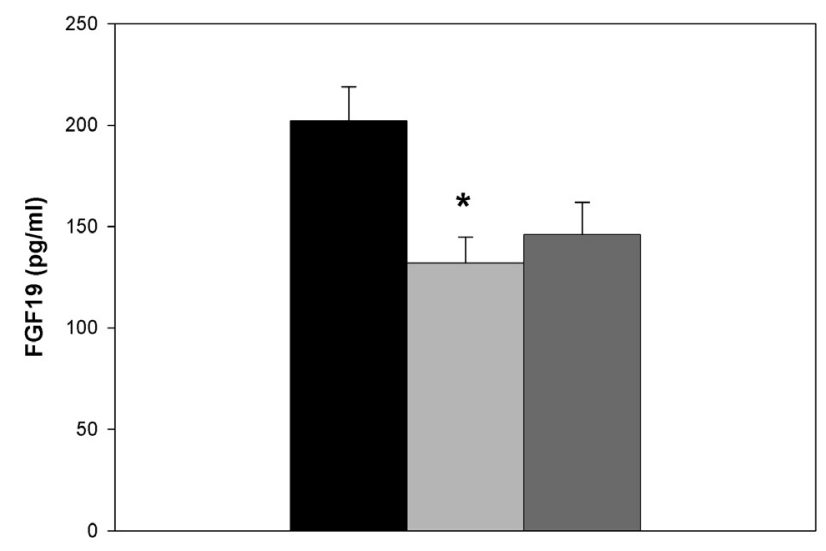

$$
\begin{aligned}
& \text { Control group } \\
& \square \text { Obese group } \\
& \square \text { T2DM group }
\end{aligned}
$$

Fig. 1. Serum FGF-19 concentrations in control group (black bar, $n=30$ ), obese nondiabetic group (light grey bar, $n=29$ ) and type 2 DM group (dark grey bar, $n=19$ ). Values are means \pm S.E.M. Statistical significance is from One-way ANOVA or ANOVA on Ranks as appropriate. ${ }^{*} \mathrm{p}<0.05$ vs. control group.

serum triglyceride concentrations, while blood glucose, HOMA index and glycated hemoglobin slightly but significantly increased. Other parameters including BMI were not affected by fenofibrate treatment. Insulin sensitivity of T2DM group was significantly lower relative to control group and was not affected by fenofibrate treatment (data not shown here, previously described in (Haluzik et al. 2009).

The influence of obesity and obesity/type 2 diabetes mellitus on FGF-19 levels and the relationship of FGF-19 levels with anthropometric and metabolic parameters

Circulating concentrations of FGF-19 reached the highest levels in lean control subjects $(202.2 \pm 16.7$ $\mathrm{pg} / \mathrm{ml}$ ), with a non-significant tendency towards lower levels in T2DM group $(146.4 \pm 15.9 \mathrm{pg} / \mathrm{ml})$ and a further, statistically significant, decrease in the obese non-diabetic group $(132.1 \pm 12.7 \mathrm{pg} / \mathrm{ml}, \quad \mathrm{p}<0.05)$. No significant difference in FGF-19 levels was observed between T2DM and obese group (Fig. 1).

In a combined population of all three groups as well as in the subpopulation of control subjects combined with obese non-diabetic patients FGF-19 concentrations significantly negatively correlated with BMI $(r=-0.309$, $\mathrm{p}<0.05$ for the whole population and $\mathrm{r}=-0.343, \mathrm{p}<0.05$ for Control + Obese subgroup) and leptin $(\mathrm{r}=-0.282$, $\mathrm{p}<0.05$ for the whole population and $\mathrm{r}=-0.365, \mathrm{p}=0.005$
Serum FGF 19 levels
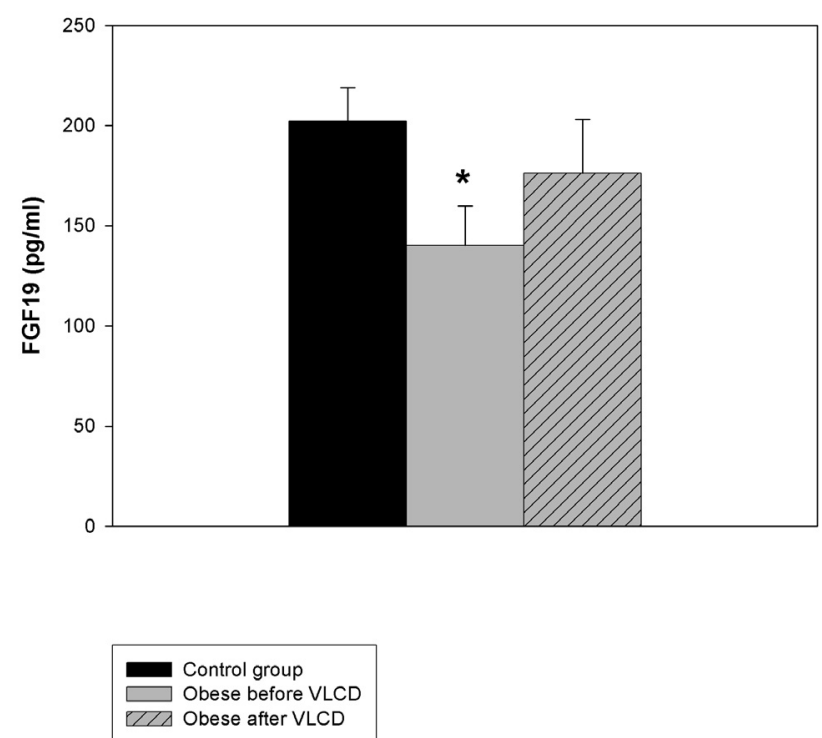

Fig. 2. Serum FGF-19 concentrations in control group (black bar, $\mathrm{n}=30$ ), obese patients before (light grey bar, $\mathrm{n}=12$ ) and after (dashed bar, $n=12$ ) three weeks of very low calorie diet (VLCD). Values are means \pm S.E.M. Statistical significance is from Oneway ANOVA or ANOVA on Ranks and from paired t-test or Wilcoxon Signed Rank Test as appropriate. ${ }^{*} p<0.05$ vs. control group.

for Control + Obese subgroup) and significantly positively with adiponectin $(\mathrm{r}=0.289, \mathrm{p}<0.05$ for the whole population and $\mathrm{r}=0.289, \mathrm{p}<0.05$ for Control + Obese subgroup). In contrast, no such relationship could be seen in the T2DM subgroup. FGF-19 levels were not significantly related to age, serum blood glucose, triglycerides, insulin and cholesterol or HOMA index in any of the studied groups.

The influence of VLCD, fenofibrate treatment and hyperinsulinemia during the clamp on serum FGF-19 levels

Three weeks of VLCD did not significantly influence serum FGF-19 levels in obese group (140.2 \pm 19.7 vs. $176.1 \pm 27.1 \mathrm{pg} / \mathrm{ml}, \mathrm{p}=0.369)$ (Fig. 2), while 3 months of treatment with fenofibrate significantly decreased FGF-19 concentrations in T2DM patients (194.6 \pm 26.2 vs. $107.5 \pm 25.0 \mathrm{pg} / \mathrm{ml}, \mathrm{p}=0.007$ ) (Fig. 3). Three hours of acute hyperinsulinemia during isoglycemic-hyperinsulinemic clamp tended to decrease FGF-19 levels in both healthy and T2DM subjects, but the difference did not reach statistical significance (214.4 \pm 15.0 vs. $145.7 \pm 19.9 \mathrm{pg} / \mathrm{ml}, \mathrm{p}=0.130$ for control and $198.6 \pm 18.0$ vs. $147.2 \pm 24.8 \mathrm{pg} / \mathrm{ml}, \quad \mathrm{p}=0.519$ for diabetic group). Nevertheless, there was a significant drop in FGF-19 concentrations in T2DM group after 


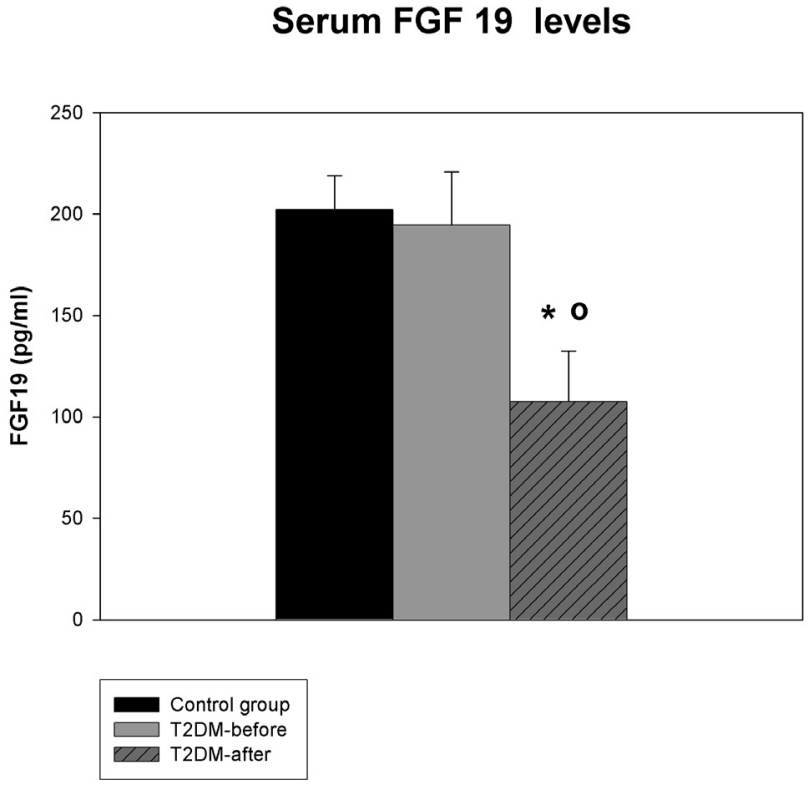

Fig. 3. Serum FGF-19 concentrations in control group (black bar, $n=10$ ), type 2 DM group before (dark grey bar, $n=11$ ) and after three months of fenofibrate treatment (dashed bar, $n=11$ ). Values are mean \pm S.E.M. Statistical significance is from One-way ANOVA or ANOVA on Ranks and from paired t-test or Wilcoxon Signed Rank Test as appropriate. ${ }^{*} \mathrm{p}<0.05$ vs. control group, ${ }^{\circ} p<0.05$ vs. T2DM group before treatment.

90 minutes of the clamp $(198.6 \pm 18.0$ vs. $121.1 \pm 21.0$ $\mathrm{pg} / \mathrm{ml}, \mathrm{p}<0.001)$, while no such change could be seen in the control group $(214.4 \pm 15.0$ vs. $188.0 \pm 41.1 \mathrm{pg} / \mathrm{ml}$, $\mathrm{p}=0.483$ ) (Fig. 4). In T2DM group three months of fenofibrate treatment resulted in markedly decreased initial FGF-19 concentrations with no further change in its levels in the course of the isoglycemichyperinsulinemic clamp $(95.7 \pm 16.5$ vs. $114.1 \pm 18.0$ vs. $112.5 \pm 25.8 \mathrm{pg} / \mathrm{ml}, \mathrm{p}=0.264$ ) (Fig. 4).

\section{Discussion}

FGF-19 is a novel endocrine and paracrine regulator which plays central role in the suppression of bile acid synthesis and secretion. As bile acid metabolism is tightly connected to other metabolic pathways, especially those of lipids (Insull 2006, Lefebvre et al. 2009), FGF-19 was suggested to participate also in the regulation of other processes, including cholesterol, lipoprotein, triglyceride and glucose metabolism (Tomlinson et al. 2002, Fu et al. 2004). Rodents with FGF-19 overexpression have decreased body weight and improved glucose tolerance and insulin sensitivity compared to their wild-type littermates. FGF-19 overexpressing mice are also protected from high fat dietinduced weight gain (Tomlinson et al. 2002). Similar

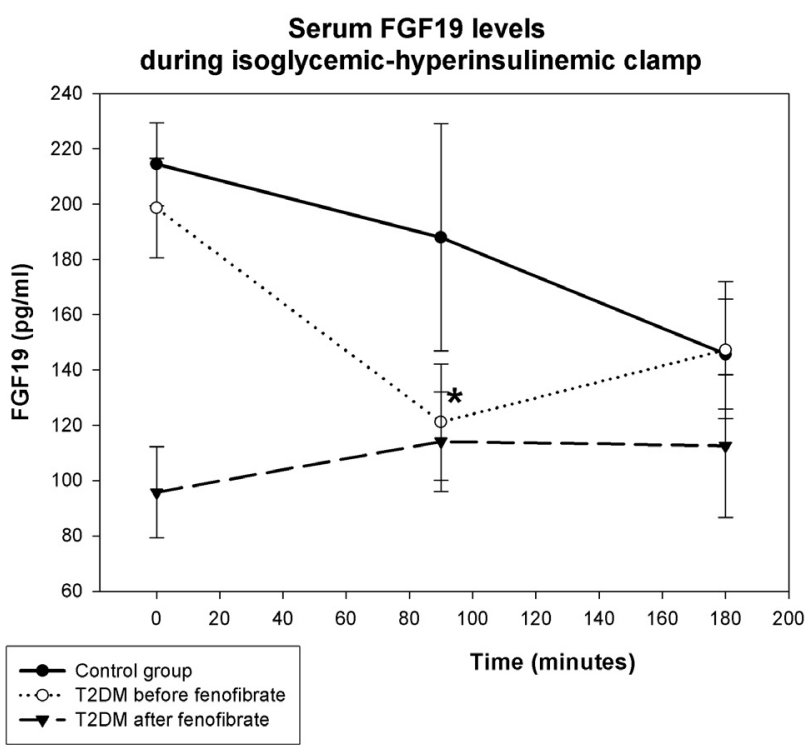

Fig. 4. Changes of FGF19 concentrations during isoglycemichyperinsulinemic clamp in control group of healthy females (filled circles, $n=10$ ) and obese females with type 2 DM before (open circles, $\mathrm{n}=11$ ) and after three months of treatment with PPAR-a agonist fenofibrate (filled triangles, $n=11$ ). Statistical significance is from One-way RM ANOVA on Ranks. * $p<0.05$ vs. baseline value of the respective group.

results were seen in mice treated with exogenous recombinant FGF-19, which display reduced body weight and decreased serum glucose, insulin, cholesterol and triglyceride levels (Fu et al. 2004).

In humans, data concerning the relation of FGF-19 to metabolic parameters are less concise. In our previous study, we have demonstrated that FGF-19 levels were not affected by nutritional status in severely underweight patients with anorexia nervosa, nor were they related to any of the investigated metabolic parameters (Dostalova et al. 2008a). Schreuder et al. (2010) did not find any influence of insulin resistance (IR) as assessed by HOMA index on intestinal FGF-19 production in patients with non-alcohol fatty liver disease (NAFLD), though the suppressing effect of FGF-19 on bile acid synthesis was impaired in IR patients (Schreuder et al. 2010). In a recently conducted study by Brufau et al. (2010) FGF-19 levels did not differ between type 2 diabetic patients and control subjects. In contrast, Reiche et al. (2010) reported a negative correlation between FGF-19 and fasting glucose in healthy subjects. Here we show that in our patients FGF-19 levels correlated inversely with body mass index, with the most pronounced differences in serum FGF-19 concentrations being in the most obese patients with BMI over 40 . T2DM group with a mean BMI of $36 \mathrm{~kg} / \mathrm{m}^{2}$ tended to 
have rather slightly decreased levels of FGF-19. A positive correlation between FGF-19 and adiponectin observed throughout the study population extends similar findings reported previously in chronically hemodialysed patients (Reiche et al. 2010). These findings may suggest a possible relationship between FGF-19 and the regulation of endocrine function of adipose tissue that has been in previous studies linked to the regulation of glucose metabolism and insulin sensitivity (Anderlova et al. 2006, Ronti et al. 2006).

Three weeks of very-low calorie diet in our study significantly reduced body weight along with the decrease in blood glucose, insulin and HOMA index and a tendency to improved lipid profile (Table 2). FGF-19 levels tended to increase but the difference did not reach statistical significance. In experimental studies fasting was associated with increased production of FGF-15 (the mouse orthologue of FGF-19) and decreased liver expression of FGF receptor 4 (FGFR4) in rodents. At the same time fasting increased the expression of CYP7A1, a key regulator enzyme in bile acid synthesis, via pathways independent of FGF-15 - FGFR4 axis (mainly through the decreased insulin-mediated suppression of CYP7A1) (Shin and Osborne 2009). Whether a similar mechanism could be applied to humans and whether FGF-19 could play a role in some adaptive responses to fasting and/or caloric restriction remains to be further determined. Collectively, these findings suggest, that serum FGF-19 is at least partially influenced by nutritional status and body weight, especially in the higher BMI ranges. In contrast, the absence of a clear association of circulating FGF-19 to parameters of glucose metabolism is in line with previous reports in humans, which so far failed to demonstrate an explicit and causal relation between FGF19 and glucose metabolism disorders (Brufau et al. 2010, Schreuder et al. 2010).

The metabolism of bile acids on one hand and cholesterol and triglycerides on the other hand is tightly coupled. Bile acids represent the primary pathway for cholesterol catabolism and bile acid sequestration with resins is connected with decreased total and LDL cholesterol, while increasing HDL cholesterol and triglycerides (Shepherd et al. 1980, Beil et al. 1982, Insull 2006). The most important link between bile acid and lipid metabolism is thought to be Farnesoid $\mathrm{X}$ receptor, the activator of FGF-19 synthesis. FRX inhibits the expression of several lipogenic genes, while promoting the activity of lipoprotein lipase and stimulating VLDL receptors (reviewed in (Lefebvre et al.
2009, Smelt 2010). FXR also activates PPAR- $\alpha$ receptors promoting thus the catabolism of free fatty acids (Pineda Torra et al. 2003). The exact role of FGF-19 in these interplays is currently unknown. In animals, FGF-19 has been shown to inhibit the expression of several ratelimiting enzymes involved in fatty acid synthesis (Tomlinson et al. 2002, Fu et al. 2004). In humans, Brufau et al. (2010) have demonstrated that treatment with bile acid sequestrant colesevelam improved diabetic control and decreased basal and postprandial FGF-19 concentrations in both T2DM and healthy subjects. However, no relationships between parameters of glucose metabolism and changes in FGF-19 levels or bile acid metabolism were found. In the present study no correlation between FGF-19 levels and the parameters of lipid metabolism could be observed.

As fibrates as triglyceride lowering agents act, similarly to FXR, via activation of PPAR- $\alpha$, in the third part of our study we examined the influence of three months of fenofibrate administration on serum levels of FGF-19 to test the hypothesis that changes in FGF-19 may contribute to positive effects of fibrate treatment. Fenofibrate administration in hypertriglyceridemic T2DM patients decreased triglyceride levels while body weight, total and HDL cholesterol remained unchanged. FGF-19 levels after fenofibrate treatment markedly decreased. These findings argue against the hypothesis, that fibrate-induced activation of PPAR $\alpha$ might involve also the induction of FGF-19.

A rapidly growing body of evidence is supporting the importance of bile acids and bile acid receptors in the regulation of insulin action (reviewed in (Lefebvre et al. 2009)). In vitro and animal studies suggest that FXR activation improves insulin sensitivity and insulin-stimulated glucose uptake (Cariou et al. 2006, Zhang et al. 2006). Stimulation of hepatic FXR resulted in decreased hepatic gluconeogenesis, increased glycogen synthesis and decreased plasma glucose levels (Ma et al. 2006, Zhang et al. 2006). In mice, insulin was shown to up-regulate hepatic FGF receptor 4 (FGFR4), the major hepatic FGFR isoform (Shin and Osborne 2009). Similarly to FGF-19, insulin also decreases bile acid synthesis by suppressing the expression of its ratelimiting CYP7A1 enzyme. It was demonstrated that the mouse FGF-orthologue, FGF-15, and insulin act in liver partially via the same pathways, with forkhead transcriptional factor 1 (FoxO1), a factor controlling the expression of CYP7A1 as well as several gluconeogenetic genes, being the key converging node 
(Shin and Osborne 2009). To examine the influence of short-term hyperinsulinemia on circulating FGF-19 levels we performed hyperinsulinemic-isoglycemic clamp in the subgroup of diabetic patients undergoing treatment with fenofibrate and in an age- and sex-matched control group. Starting at comparable levels, in T2DM group FGF-19 showed a steep dropdown at 90 minutes followed by a slow rise towards the end of the procedure. In healthy lean controls FGF-19 slowly decreased throughout the clamp terminating at almost the exact levels as in T2DM group. Interestingly, with basal levels of FGF-19 almost halved after 3 months of fenofibrate treatment, no significant effect of acute hyperinsulinemia on serum FGF-19 during the clamp was observed. Our current data do not allow us to unravel the exact mechanisms of insulin-mediated FGF-19 regulation and its modulation by fibrate therapy, but these findings suggest the existence of other regulatory pathways, independent of intestinal bile acid actions. A direct effect of insulin on FGF-19 production might be one of the options. However, other factors affected by both procedures (clamp and fenofibrate treatment) could constitute further links between insulin and FGF-19 production. One of the candidates might be free fatty acids (FFA), as they are almost completely inhibited during hyperinsulinemicisoglycemic clamp (Stumvoll et al. 2000) and they are also reduced by fibrate-mediated PPAR $\alpha$ activation. As we did not assess FFA levels during the clamp substudy, this and other possible mechanisms remain subject of further investigations.

Taken together, our study demonstrated that FGF-19 levels correlated inversely with BMI and were significantly increased in severely obese patients compared to lean healthy controls. Very low calorie diet showed no significant effect on FGF-19 levels, while PPAR $\alpha$ agonist treatment decreased them significantly. Acute hyperinsulinemia tended to reduce FGF-19 suggesting the existence of other regulatory pathways besides the well-established intestinal bile acid regulation. Though no significant relationship of FGF-19 to the presence of T2DM or various measures of glucose metabolism and insulin sensitivity could be established, the role of FGF-19 in the complex net of reactions integrating bile acid, lipid and glucose metabolism remains an appealing challenge for further investigations.

\section{Conflict of Interest}

There is no conflict of interest.

\section{Acknowledgements}

Supported by IGA10024-4.

\section{References}

ANDERlOVA K, DOLEZAlOVA R, HOUSOVA J, BOSANSKA L, HALUZIKOVA D, KREMEN J, SKRHA J, HALUZIK M: Influence of PPAR-alpha agonist fenofibrate on insulin sensitivity and selected adipose tissuederived hormones in obese women with type 2 diabetes. Physiol Res 56: 579-586, 2007.

ANDERlOVA K, KREMEN J, DOLEZALOVA R, HOUSOVA J, HALUZIKOVA D, KUNESOVA M, HALUZIK $\mathrm{M}$ : The influence of very-low-calorie-diet on serum leptin, soluble leptin receptor, adiponectin and resistin levels in obese women. Physiol Res 55: 277-283, 2006.

BEIL U, CROUSE JR, EINARSSON K, GRUNDY SM: Effects of interruption of the enterohepatic circulation of bile acids on the transport of very low density-lipoprotein triglycerides. Metabolism 31: 438-444, 1982.

BRUFAU G, STELLAARD F, PRADO K, BLOKS VW, JONKERS E, BOVERHOF R, KUIPERS F, MURPHY EJ: Improved glycemic control with colesevelam treatment in patients with type 2 diabetes is not directly associated with changes in bile acid metabolism. Hepatology 52: 1455-1464, 2010.

CARIOU B, VAN HARMELEN K, DURAN-SANDOVAL D, VAN DIJK TH, GREFHORST A, ABDELKARIM M, CARON S, TORPIER GR, FRUCHART J-C, GONZALEZ FJ, KUIPERS F, STAELS B: The farnesoid X receptor modulates adiposity and peripheral insulin sensitivity in mice. J Biol Chem 281: 11039-11049, 2006.

DOSTALOVA I, KAVALKOVA P, HALUZIKOVA D, LACINOVA Z, MRAZ M, PAPEZOVA H, HALUZIK M: Plasma concentrations of fibroblast growth factors 19 and 21 in patients with anorexia nervosa. $J$ Clin Endocrinol Metab 93: 3627-3632, 2008a.

FU L, JOHN LM, ADAMS SH, YU XX, TOMLINSON E, RENZ M, WILLIAMS PM, SORIANO R, CORPUZ R, MOFFAT B, VANDLEN R, SIMMONS L, FOSTER J, STEPHAN J-P, TSAI SP, STEWART TA: Fibroblast growth factor 19 increases metabolic rate and reverses dietary and leptin-deficient diabetes. Endocrinology 145: 2594-2603, 2004. 
HALUZIK MM, ANDERLOVA K, DOLEZALOVA R, ADAMIKOVA A, HALUZIKOVA D, HOUSOVA J, SVACINA S, HALUZIK M: Serum adipocyte fatty acid binding protein levels in patients with type 2 diabetes mellitus and obesity: the influence of fenofibrate treatment. Physiol Res 58: 93-99, 2009.

HOLT JA, LUO G, BILLIN AN, BISI J, MCNEILL YY, KOZARSKY KF, DONAHEE M, WANG DY, MANSFIELD TA, KLIEWER SA, GOODWIN B, JONES SA: Definition of a novel growth factor-dependent signal cascade for the suppression of bile acid biosynthesis. Genes Dev 17: 1581-1591, 2003.

CHOI M, MOSCHETTA A, BOOKOUT AL, PENG L, UMETANI M, HOLMSTROM SR, SUINO-POWELL K, XU HE, RICHARDSON JA, GERARD RD, MANGELSDORF DJ, KLIEWER SA: Identification of a hormonal basis for gallbladder filling. Nat Med 12: 1253-1255, 2006.

INAGAKI T, CHOI M, MOSCHETTA A, PENG L, CUMMINS CL, MCDONALD JG, LUO G, JONES SA, GOODWIN B, RICHARDSON JA, GERARD RD, REPA JJ, MANGELSDORF DJ, KLIEWER SA: Fibroblast growth factor 15 functions as an enterohepatic signal to regulate bile acid homeostasis. Cell Metab 2: 217-225, 2005.

INSULL W JR: Clinical utility of bile acid sequestrants in the treatment of dyslipidemia: a scientific review. South Med J 99: 257-273, 2006.

ITOH N, ORNITZ DM: Evolution of the Fgf and Fgfr gene families. Trends Genet 20: 563-569, 2004.

LEFEBVRE P, CARIOU B, LIEN F, KUIPERS F, STAELS B: Role of bile acids and bile acid receptors in metabolic regulation. Physiol Rev 89: 147-191, 2009.

LUNDASEN T, GALMAN C, ANGELIN B, RUDLING M: Circulating intestinal fibroblast growth factor 19 has a pronounced diurnal variation and modulates hepatic bile acid synthesis in man. $J$ Intern Med 260: 530-536, 2006.

MA K, SAHA PK, CHAN L, MOORE DD: Farnesoid X receptor is essential for normal glucose homeostasis. $J$ Clin Invest 116: 1102-1109, 2006.

MATTHEWS DR, HOSKER JP, RUDENSKI AS, NAYLOR BA, TREACHER DF, TURNER RC: Homeostasis model assessment: insulin resistance and beta-cell function from fasting plasma glucose and insulin concentrations in man. Diabetologia 28: 412-419, 1985.

NISHIMURA T, UTSUNOMIYA Y, HOSHIKAWA M, OHUCHI H, ITOH N: Structure and expression of a novel human FGF, FGF-19, expressed in the fetal brain. Biochim Biophys Acta 1444: 148-151, 1999.

PINEDA TORRA I, CLAUDEL T, DUVAL C, KOSYKH V, FRUCHART J-C, STAELS B: Bile acids induce the expression of the human peroxisome proliferator-activated receptor \{alpha\} gene via activation of the farnesoid X receptor. Mol Endocrinol 17: 259-272, 2003.

REICHE M, BACHMANN A, LÖSSNER U, BLÜHER M, STUMVOLL M, FASSHAUER M: Fibroblast growth factor 19 serum levels: relation to renal function and metabolic parameters. Horm Metab Res 42: 178-181, 2010.

RONTI T, LUPATTELLI G, MANNARINO E: The endocrine function of adipose tissue: an update. Clin Endocrinol (Oxf) 64: 355-365, 2006.

SHEPHERD J, PACKARD CJ, BICKER S, LAWRIE TDV, MORGAN HG: Cholestyramine promotes receptormediated low-density-lipoprotein catabolism. $N$ Engl J Med 302: 1219-1222, 1980.

SHIN DJ, OSBORNE TF: FGF15/FGFR4 integrates growth factor signaling with hepatic bile acid metabolism and insulin action. J Biol Chem 284: 11110-11120, 2009.

SCHAAP FG, VAN DER GAAG NA, GOUMA DJ, JANSEN PL: High expression of the bile salt-homeostatic hormone fibroblast growth factor 19 in the liver of patients with extrahepatic cholestasis. Hepatology 49: 1228-1235, 2009.

SCHREUDER TC, MARSMAN HA, LENICEK M, VAN WERVEN JR, NEDERVEEN AJ, JANSEN PL, SCHAAP FG: The hepatic response to FGF19 is impaired in patients with nonalcoholic fatty liver disease and insulin resistance. Am J Physiol Gastrointest Liver Physiol 298: G440-G445, 2010.

SMELT AHM: Triglycerides and gallstone formation. Clin Chim Acta 411: 1625-1631, 2010.

STUMVOLL M, JACOB S, WAHL HG, HAUER B, LOBLEIN K, GRAUER P, BECKER R, NIELSEN M, RENN W, HARING H: Suppression of systemic, intramuscular, and subcutaneous adipose tissue lipolysis by insulin in humans. J Clin Endocrinol Metab 85: 3740-3745, 2000. 
TOMLINSON E, FU L, JOHN L, HULTGREN B, HUANG X, RENZ M, STEPHAN JP, TSAI SP, POWELLBRAXTON L, FRENCH D, STEWART TA: Transgenic mice expressing human fibroblast growth factor-19 display increased metabolic rate and decreased adiposity. Endocrinology 143: 1741-1747, 2002.

XIE MH, HOLCOMB I, DEUEL B, DOWD P, HUANG A, VAGTS A, FOSTER J, LIANG J, BRUSH J, GU Q, HILLAN K, GODDARD A, GURNEY AL: FGF-19, a novel fibroblast growth factor with unique specificity for FGFR4. Cytokine 11: 729-735, 1999.

YU C, WANG F, JIN C, HUANG X, MCKEEHAN WL: Independent repression of bile acid synthesis and activation of c-Jun N-terminal kinase (JNK) by activated hepatocyte fibroblast growth factor receptor 4 (FGFR4) and bile acids. J Biol Chem 280: 17707-17714, 2005.

YU C, WANG F, KAN M, JIN C, JONES RB, WEINSTEIN M, DENG C-X, MCKEEHAN WL: Elevated cholesterol metabolism and bile acid synthesis in mice lacking membrane tyrosine kinase receptor FGFR4. $J$ Biol Chem 275: 15482-15489, 2000.

ZHANG Y, LEE FY, BARRERA G, LEE H, VALES C, GONZALEZ FJ, WILLSON TM, EDWARDS PA: Activation of the nuclear receptor FXR improves hyperglycemia and hyperlipidemia in diabetic mice. Proc Natl Acad Sci U S A 103: 1006-1011, 2006. 